\title{
Health disorders in physicians, a growing problem
}

For many years now, the health of physicians has deserved special attention due to the potentially serious implications for themselves and their patients.

Traditionally, most people assumed that physicians seldom or never got sick because they were convinced that they knew how to take care of themselves, prevent diseases or heal rapidly considering that they knew medical science.

Such naive beliefs were probably based on the conviction that physicians could never be wrong and should therefore be healthy.

Nothing could be further from the reality, since physicians very frequently develop conditions that prevent them from enjoying good health.

Recent reports from the USA point out that the health of physicians has worsened progressively due to an increase in burnout as part of their clinical practice. Likewise, current data suggest that approximately 400 physicians commit suicide in the USA every year. ${ }^{1}$

A study observed, through a survey, a high and increasing rate of physician burnout. Among the 7000 physicians who completed the survey, $54 \%$ indicated that they had at least one burnout symptom in 2014, compared to $45 \%$ in 2011, which meant approximately $10 \%$ more -an alarming increase. Based on this result, probably more than half of physicians in the USA suffer a certain level of burnout syndrome. Dissatisfaction with the intense level of work and inadequate remunerations also showed an increase in the survey, but the same investigators also pointed out that this was not surprising because they knew that, as a whole, physicians work more and make less money. ${ }^{1}$

A study conducted at Hospital Italiano de Buenos Aires showed that $28.8 \%$ of surveyed medical residents had burnout symptoms associated with a loss of meaning in life and a lack of a career project. $^{2}$

Data from Australia and New Zealand showed that approximately 1 in 3 physicians had a burnout symptom. It was observed, in an analysis, that the burnout rate was over $60 \%$ among practicing physicians. An assessment of surgeon burnout in New Zealand revealed that the highest risk factors included female physicians who frequently worked an average of more than 60 hours a week. ${ }^{3}$
Recently, a study conducted by investigators from the University of Oxford included the completion of a questionnaire sent in 2014 to all the United Kingdom medical graduates of 1974 and 1977. A total of 3690 physicians agreed to complete it and answered the question "Do you feel that working as a doctor has had any adverse effects on your own health or wellbeing?" The result showed that $44 \%$ of all physicians answered "yes." Among these, $75 \%$ mentioned that they suffered "'stress/intense working life/ difficult work-life balance/ workload." ${ }^{4}$

The causes of physician burnout are intricate. In general, burnout syndrome is described as a loss of enthusiasm for one's job, leading to a progressive dissatisfaction in one's routine professional practice.

It is more frequently observed together with an increase in workload, the continuous pressure of time, the low remunerations offered by private facilities, an inadequate patient care, the endless red tape, etc. In addition, more frequently, facilities are transitioning from paper to electronic medical records, and this has undoubtedly led to hurdles in medical practice. The problem is that these were designed to maximize income instead of improving medical care; therefore, a detrimental technological barrier has been established between physicians and patients. A few years ago, a colleague and I were in a noted hospital in the USA talking to the head of the Department of Neonatology and, among other things, she commented " $I$ ' $m$ really worried because residents spend more time on their computers than with their patients and they don't even pay attention to the parents of hospitalized newborns." Without a doubt, this is one of the many problems and disorders occurring in the setting of patient care due to the overwhelming technological development related to medicine and the financial interests of companies making such developments because they care more about obtaining a profit than about taking actions tending to favor patients.

The common factors observed in physicians who have progressive burnout include depression, stress, detachment, emotional disorders (sadness, loss of affection), drug, alcohol and opiate abuse, among others. Self-medication is really common and very disturbing because physicians are more prone to use tranquilizers, sedatives, and 
stimulants than the general population. Physicians from different countries now buy more of these and also illegal drugs, but there is no data on what occurs in Argentina. It is important to know the frequency of purchase and use of these substances among physicians, both those with many years of experience and younger ones, i.e., medical and fellow residents. The power of knowing the magnitude of this problem would allow us to take actions and implement strategies to create programs aimed at reducing the health problems of physicians and, thus, prevent them from using improper medications and drugs, which are undoubtedly very harmful to them and may lead them to serious actions, such as suicide, and health disorders that hinder their medical practice and end their career.

Another extremely important aspect is that of specific mental health symptoms, especially depression, anxiety, and chronic post-traumatic stress, in addition to suicidal ideation. Mental health disorders have been receiving even greater attention in recent years.

In the United Kingdom, the rate of suicidal attempt has been estimated at about $6 \%$ among those with many years of experience and at $23 \%$ among younger physicians; and the frequency of suicide is 2-5 times higher than in the general population. ${ }^{4}$

Likewise, a mental health survey administered to physicians and medical students in Australia observed substantially higher rates of mental health problems and suicidal attempt compared to the general population and other professions. ${ }^{3}$ However, reports on the prevalence of mental disorders among physicians are contradictory and probably varying, even among developed countries.

In relation to the factors that have an impact on mental health problems, it is worth mentioning the conflict between medical practice and personal life, which is a high risk factor for the different disorders mentioned here, such as burnout, depression, stress, anxiety, and suicide.

To improve and prevent such disorders, it is critical to have adequate knowledge on the reasons for the worsening of physicians' health. This way, different preventive actions may be taken in an attempt to reduce situations that are detrimental to everyday practice with patients.
Not only is it necessary to identify the causes, but also to understand them as best we can so that data help physicians who already have health problems to improve and regain their full medical practice.

Different appropriate interventions should aim at eliminating or reducing exposure to deficient and inadequate working conditions, either due to excessive working hours, low remunerations for their hard work, extensive red tape, and the problems associated with current technology use.

Available support should be effectively communicated and its acceptance should be encouraged so that colleagues with no health problems become aware of their harmful impact because they are also potential victims.

Without a doubt, a good health is ideal for physicians because it will allow them to comply with the essential action of medicine: patient care. Gianantonio, our unforgettable great teacher, used to say "to help, to take care, to comfort, always; cure... sometimes".

José María Ceriani Cernadas, M.D. Editor

http:/ / dx.doi.org/10.5546/aap.2019.eng.138

To cite: Ceriani Cernadas JM. Health disorders in physicians, a growing problem. Arch Argent Pediatr 2019;117(3):138-139.

\section{REFERENCES}

1. Grinspoon P. Physician burnout can affect your health. Boston: Harvard Health Publishing. Harvard MedicalSchool; 2018 June 22. [Accessed on: February 22 $\left.{ }^{\text {nd }}, 2019\right]$ Available at: https: / / www.health.harvard.edu/blog/physicianburnout-can-affect-your-health-2018062214093

2. Muñoz AM, Fossati V, Llera JG, Grande Ratti MF, Antonietti CA. ¿Cuál es la relación entre el síndrome de burnout, el sentido de la vida y el proyecto de vida laboral en los médicos residentes? Una perspectiva logoterapéutica. Rev Hosp Ital B Aires. 2017;38(3):96-104.

3. The Royal Australasian College of Physicians. Health of Doctors Position Statement May 2013. [Accessed on: February 22 $\left.{ }^{\text {nd }}, 2019\right]$ Available at: https: / / www.racp.edu. au/docs / default-source / advocacy-library/ pa-pos-healthof-doctors-2013.pdf

4. Smith F, Goldacre MJ, Lambert TW. Adverse effects on health and wellbeing of working as a doctor: views of the UK medical graduates of 1974 and 1977 surveyed in 2014. J R Soc Med. 2017;110(5):198-207.

5. Brooks SK, Gerada G, Chalder T. Review of literature on the mental health of doctors: Are specialist services needed? J Ment Health. 2011;20(2):146-56. 